\title{
Natural History and Clinical Significance of Arrhythmias After Acute Cardiac Infarction
}

\author{
D. C. FLUCK ${ }^{\star}$, E. OLSENt, B. L. PENTECOST, M. THOMAS, S. J. FILLMORE, \\ J. P. SHILLINGFORD, AND J. P. D. MOUNSEY \\ From the Departments of Medicine and Pathology, and the M.R.C. Cardiovascular Research Unit, Postgraduate \\ Medical School, Hammersmith Hospital, London W.12
}

Continuous monitoring of the electrocardiogram has shown the incidence of arrhythmias in acute myocardial infarction to be much higher than was previously thought. With this method, Julian, Valentine, and Miller (1964) found a serious arrhythmia in as many as 56 per cent of their patients, whereas in an earlier study with routine electrocardiograms, Master, Dack, and Jaffe (1937) found an arrhythmia in only 14 per cent of their patients, premature beats being excluded.

An increase in the mortality rate has been noted in association with certain arrhythmias developing during the course of acute myocardial infarction (Woods and Barnes, 1942; Billings et al., 1949; Beard et al., 1960), and it is possible that a more detailed study of these may lead to improvement in their management, and so reduce the mortality in this disease.

This paper describes the natural history and clinical significance of the arrhythmias occurring in 50 consecutive patients with acute myocardial infarction. A new clinical grouping of the arrhythmias is proposed based on the over-all cardiac response to the arrhythmia. Their hæmodynamic effects are discussed and also their ætiology in relation to necropsy findings. Finally the prognosis and management of individual groups is described.

\section{SUBJECTS AND METHODS}

Fifty unselected consecutive patients admitted to the Intensive Care Coronary Unit at the Hammersmith Hospital were studied. All were suffering from acute myocardial infarction. The diagnosis was based on the

Received April 13, 1966.

$\star$ Present address: Guy's Hospital, London S.E.1.

† Supported by a grant from the British Heart Foundation. clinical history associated with pathognomonic electrocardiographic changes, with $Q$ waves, ST elevation, and $T$ wave inversion in 42 patients; in eight patients, however, electrocardiographic changes suggestive of infarction (ST and $T$ wave changes with $Q$ waves, or LBBB) were seen, supported by a history of prolonged cardiac pain and a significant rise of the lactate dehydrogenase enzyme (above 200 units, with over 50\% heatstable). Confirmation at necropsy was obtained in nine patients.

There were 40 men and 10 women. The average age of the men was 57.8 years, with a range of 32 to 76 years, and of the women it was $58 \cdot 8$, with a range of 42 to 73 years. Forty patients were admitted suffering from their first attack of cardiac infarction, of whom 14 had had previous angina; eight patients had a clear history of a previous infarct, supported by electrocardiographic evidence in five; the remaining two patients had had more than one previous infarct. The electrocardiographic evidence of the site of the recent infarct was classified as anterior in 22, posterior in five, and combined in 17 patients. In the remaining six, previous infarcts in two and the presence of left bundle-branch block in four made the siting of the recent acute infarct difficult. With four exceptions, all patients were admitted to hospital within 48 hours of the onset of infarction, 21 patients being admitted within six hours. Only 12 of the 50 patients were known to be hypertensive, though a higher incidence of previous hypertension might have been found if blood pressure measurements before infarction had always been available. One patient had diabetes. Twenty-one patients showed radiological evidence of pulmonary œdema.

During the first week after admission patients were treated in the intensive care ward and special nursing care and observation were provided day and night. The pulse and blood pressure were recorded every half-hour initially. Oscilloscopes were placed in the intensive care ward, in the Sister's office, and in the cardiac laboratory, so that the whole team could be kept informed as closely as possible of the patient's progress. Signs of 


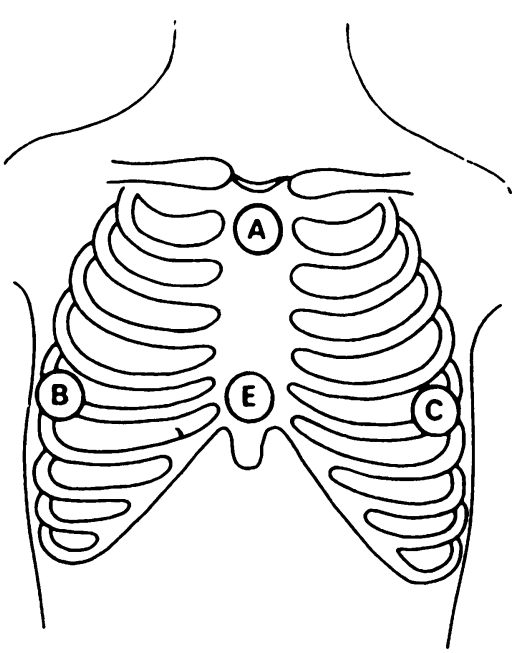

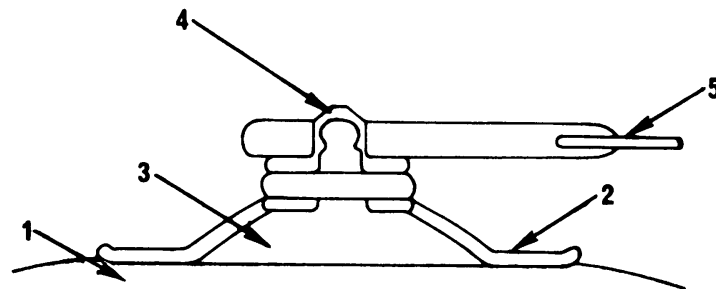

Fig. 1b.-Detail of press-stud electrode. 1=chest wall; $2=$ plastic cup; $3=$ Beckman's jelly; $4=$ press-stud electrode; $5=$ electrocardiographic lead.

Fig. 1a.-Position of press-stud electrode on chest wall. $\mathrm{B}-\mathrm{A}=$ right chest lead; $\mathrm{C}-\mathrm{A}=$ left chest lead; $\mathrm{E}=$ earth.

early heart failure or complications, such as a pericardial friction rub, were carefully looked for. Standard electrocardiograms, chest radiographs, and serum enzyme and electrolyte estimations were performed routinely. During the course of this period of intensive care and investigation every effort was made to encourage rest, to allay anxiety, and to disturb the patients as little as possible.

Continuous recording of the electrocardiogram was begun immediately, on admission to hospital. Two selected electrocardiographic leads were recorded on magnetic tape for between two to seven days, the magnetic tape being changed every 24 hours. After the first week continuous recording was stopped provided all serious arrhythmias had ceased, and thereafter the electrocardiogram was monitored on a bedside oscilloscope for two to four weeks. Initially standard leads were used for continuous recording but later special bipolar chest leads were found to be preferable as they allowed free movement of the limbs. Fig. 1 shows the position of the electrodes on the chest. Leads were recorded between $A$ and $B$ and between $A$ and $C$ (Fig. 1a), giving tracings broadly similar to conventional leads II and V4, respectively. Twice the normal sensitivity was used, $1 \mathrm{mV}$ being equivalent to a $2 \mathrm{~cm}$. deflection.

A satisfactory method of securing the electrocardiographic leads to the electrodes presented a technical problem, since the leads had to be easily detachable for nursing purposes. This was overcome by the use of a special press stud electrode, incorporated in a plastic cup in which the Beckman's` electrode jelly was placed (Fig. 1b) and the cup was then fixed to the chest wall by Beckman's adhesive tape. Shaving the chest was necessary to ensure good contact. The electrode usually required changing every 24 hours.

The magnetic tape was analysed subsequently by playing back the electrocardiogram on an oscilloscope, sampling a few minutes in each hour's recording. Each sample was photographed with a Cambridge camera.

* From Faraday Electronics, Blue Town, Sheerness, Kent.
The onset and cessation of arrhythmias were traced by playing preceding and subsequent portions of the tape and these were then photographed. A clinical episode suggestive of an arrhythmia, such as a faint or palpitation, could be located on the tape by signals from a clock, recorded on the tape.

In nine patients central venous or brachial arterial pressures were recorded during an arrhythmia. These pressures were taken through fine polyethylene catheters (PE60 Intramedic) attached to a P23Gb Statham strain gauge transducer. The catheters were introduced percutaneously under local anæsthetic into the antecubital vein and the brachial artery by the Seldinger technique (1953).

Necropsies were carried out in nine of the 12 patients who died: post-mortem coronary arteriography was performed in six cases. The coronary arteries were injected with Raybar Cream (barium sulphate 50\% $\mathrm{v} / \mathrm{w}$ ) and gelatin mixture according to the method employed by Harrison and Wood (1949). The injected hearts were $x$-rayed before and after the dissection which followed the method of Lumb and Hardy (1964). The pacemaker and conducting system were also studied in detail in 7 of these cases. The sino-atrial node was examined according to Hudson (1960) and the A-V node and bundle according to Lev, Widran, and Erickson (1951). Sections, however, were taken at $2 \mathrm{~mm}$. steps instead of serially. They were cut at $5 \mu$ and stained with hæmotoxylin and eosin and Weigert's elastic van Gieson method. In addition, evidence of infarction in the atrial wall was carefully looked for. Dating of the infarction was based on the criteria of Lodge-Patch (1951).

\section{RESULTS}

Grouping of Arrhythmias. We have divided the 50 patients into six groups based on the over-all cardiac response to the dominant arrhythmia during the first 10 days after infarction. These were as 
follows: (1) supraventricular tachycardia; (2) atrial transport dysfunction; (3) supraventricular bradycardia; (4) ventricular tachycardia; (5) ventricular bradycardia; (6) sinus rhythm or extrasystoles only.

The tachycardia group was composed of seven patients with various supraventricular tachycardias (atrial or nodal tachycardia, atrial flutter or fibrillation). The atrial transport defect group was composed of four patients who had either nodal rhythm or atrio-ventricular dissociation with a ventricular rate varying between 60 and 100 beats/ min. The supraventricular bradycardia group consisted of 12 patients who had episodes of slowing of the heart with either sinus rhythm or a wandering pacemaker. The ventricular tachycardia group consisted of two patients with paroxysms of this rhythm. The ventricular bradycardia group comprised eight patients with complete heart block or idio-ventricular rhythm. Ten patients had extrasystoles only and seven patients had no arrhythmias.

In this analysis, the more serious and potentially lethal arrhythmias, namely ventricular fibrillation and standstill, were looked on as complications that may interrupt the clinical course of any of the main groups described.

General Principles of Treatment. In addition to specific treatment for individual arrhythmias described later, certain broad principles of treatment were followed for all patients. First, as far as possible, anti-arrhythmic drugs with known arrhythmic or hæmodynamic complications were avoided. Thus, procaine amide and quinidine were never used. $\beta$-blocking agents were used with caution in view of the myocardial depressant action of this group of drugs. Secondly, left ventricular failure was treated by diuretics and low salt intake; only where failure failed to respond to this treatment was digitalis added. Thirdly, a fall of blood pressure was treated by postural methods, lying the patient flat and when necessary raising his legs also. Vasoconstrictor substances, such as aramine, were seldom used. Since sudden episodes of hypotenion were not infrequent during the first few days, all patients were prophylactically nursed flat during this time, even in the presence of early left ventricular failure. All patients received continuous oxygen through an M.C. face mask (Bakelite Xylonite Ltd) to combat any slight tendency to reduction in partial pressure of oxygen in their arterial blood. Cardiac arrest was treated with external cardiac massage (Kouwenhoven, Jude, and Knickerbocker, 1960) and ventricular fibrillation was terminated with external D.C. countershock, using a Lown cardioverter (Lown, Amarasingham, and Neuman, 1962).

\section{SUPRAVENTRICULAR TACHYCARDIA GROUP \\ (7 patients: 1 death)}

The atrial arrhythmias seen in the seven patients in this group all occurred within the first week of infarction after which, with two exceptions, they did not recur. The paroxysms of arrhythmia usually lasted 12 to 18 hours. During these episodes many changing arrhythmias followed one another, often interspersed with runs of sinus rhythm, but in all, atrial fibrillation developed at some point. Thus, sinus rhythm would be followed by atrial or ventricular extrasystoles, nodal rhythm, flutter, and then fibrillation, and these rhythms would frequently recur and follow one another in varied succession (Fig. 2).

The commonest type of atrial fibrillation in this group was of the so-called flutter-fibrillation variety (Jouvé, Senez, and Pierron, 1954; Spang, 1957), in which a regular atrial rate of between 300 and 400 a minute was associated with an irregular response. In addition, sudden abrupt variations in the atrial flutter-fibrillation rate were noted (e.g. from 300 to 375 to 300 to 400 a minute).

With two exceptions, the patients were in left ventricular failure as a result of the cardiac infarct, and this antedated the onset of the arrhythmia. In general they tolerated atrial fibrillation fairly well, though in the 4 patients whose clinical picture was most grave, it resulted in a fall in systolic blood pressure below $100 \mathrm{~mm}$. Hg.

Treatment was directed to improving the general state of the patient and correcting any hæmodynamic deterioration resulting from the arrhythmia, rather than to arresting the arrhythmia itself. Oxygen at 4 litres/min. was administered routinely; diuretics were given as required for left ventricular failure. Transient hypotension accompanying paroxysms of atrial fibrillation was treated by raising the legs of the patient who was already being nursed lying flat. This manœuvre was sufficient to restore systolic blood pressure to at least $100 \mathrm{~mm} . \mathrm{Hg}$ and did not appear to cause increasing breathlessness, in spite of the fact that the patients had radiological evidence of pulmonary œdema. In only one patient was it necessary to give aramine to maintain the blood pressure.

Although digitalis was given to five patients, we withheld it from the other two, since their paroxysms of rapid fibrillation were relatively short-lived and self-terminating. We did not give digitalis routinely to these patients, because of the potential danger of other serious digitalis-induced arrhythmias during the acute stages of myocardial infarction.

A point of interest was the fact that all the patients in this group had anterior cardiac infarction, as 


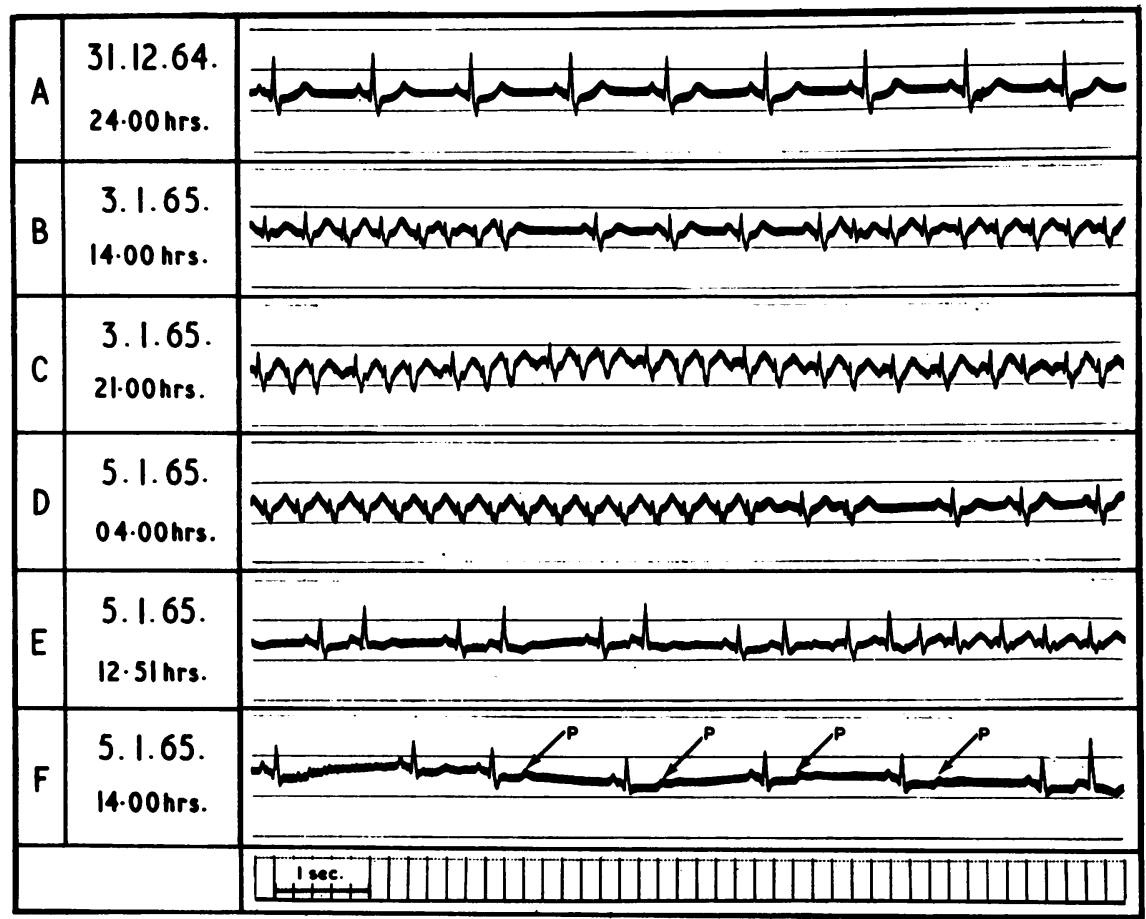

FIG. 2.-Varying paroxysmal supraventricular arrhythmias in a patient during the first week after cardiac infarction. Standard lead II. $A=$ sinus rhythm; $B=$ paroxysms of atrial fibrillation; $C=$ atrial fibrillation; $\mathrm{D}=$ atrial tachycardia (2:1-ventricular rate 165$)$ followed by sinus rhythm; $\mathrm{E}=$ coupled atrial extrasystoles followed by atrial fibrillation; $F=$ blocked coupled atrial extrasystoles (indicated by arrows).

shown in the electrocardiogram, with, in addition, lateral involvement in two patients and septal involvement in others. The anterior position of the infarct in this group was in contrast to its posterior position in the group with supraventricular bradycardia described below.

One patient in this group died. She was a 62year-old woman with a three-year previous history of angina, who developed an antero-septal infarct and then remained in borderline left ventricular failure for the following two months. On the second day after infarction frequent supraventricular ectopics developed followed by rapid atrial fibrillation (ventricular rate $200 / \mathrm{min}$.) with a fall of blood pressure to $80 \mathrm{~mm}$. Hg systolic. Aramine as well as postural treatment was needed to maintain the blood pressure. Digoxin, which had been started on admission, was then withheld; four unsuccessful attempts at D.C. cardioversion (with shocks up to 300 Watt seconds) were made. Sinus rhythm finally reappeared spontaneously 12 hours later. Her death took place eight weeks later, when she was readmitted in congestive heart failure. Terminally she again developed rapid atrial fibrillation, followed by ventricular tachycardia and ventricular fibrillation which failed to respond to cardiac massage and D.C. shock. Although arrhythmias were the immediate mode of death of this patient, the persistence of borderline left ventricular failure for two months following cardiac infarction was in itself an ominous prognostic sign. Necropsy revealed a large antero-septal myocardial infarct and extensive coronary arterial disease, details of which are described later.

In summary, the atrial arrhythmias seen in the supraventricular tachycardia group were paroxysmal, self-limiting, and relatively benign, responding to general treatment of heart failure with oxygen and diuretics and postural measures to maintain the blood pressure. They normally ceased spontaneously by the end of the first week from the time of the infarct. Digitalis was only required in the longer paroxysms of atrial fibrillation with rapid ventricular rate.

\section{Atrial Transport Dysfunction Group}

(4 patients: 1 death)

The four patients in this group had nodal rhythm or atrio-ventricular rhythm with consequent loss 


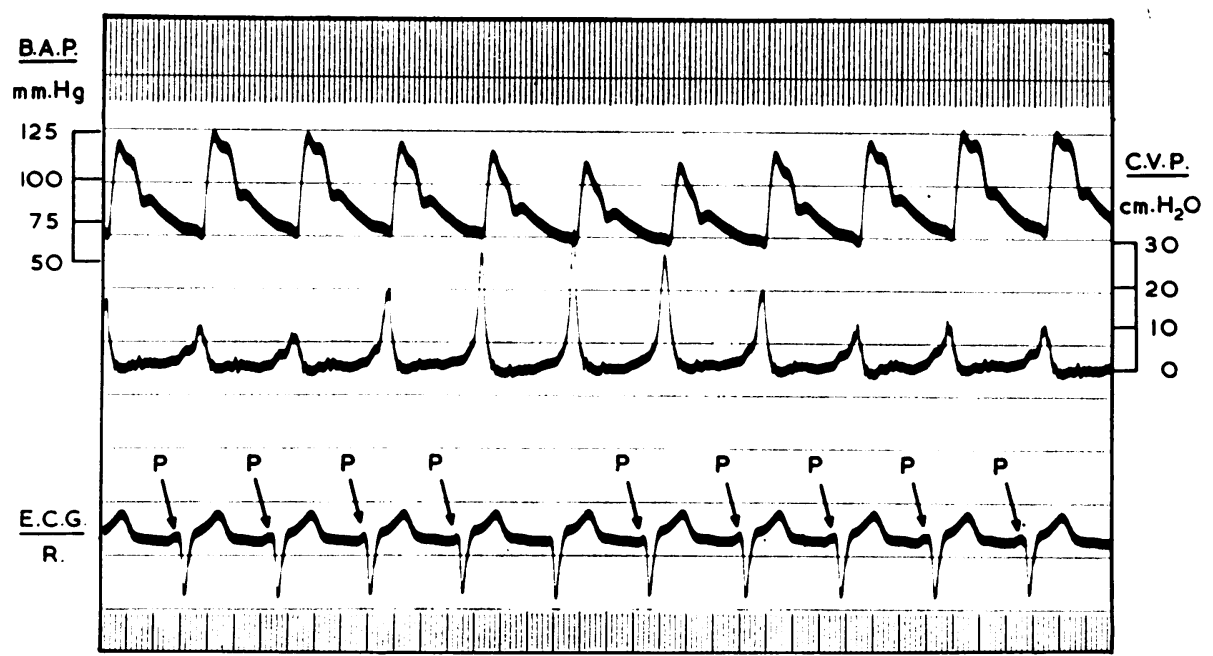

FIg. 3.-Atrio-ventricular dissociation. Simultaneous brachial arterial pressure (B.A.P.); central venous pressure (C.V.P.); and electrocardiogram (E.C.G.), right chest lead (R) (see Fig. 1). P waves move first toward and later away from QRS complex. With superimposition of $P$ on $Q R S$, cannon waves develop in central venous pressure, with simultaneous fall in brachial arterial pressure, due to loss of mechanical atrial transport function.

of mechanical atrial transport function. In these rhythms the normal sequence of atrial and ventricular contractions is disturbed to varying degrees, depending on the altered time of relationship of the $P$ and $Q R S$ waves in the electrocardiogram. In the presence of acute cardiac infarction, loss of atrial transport function may have important hæmodynamic consequences, with fall in blood pressure.

Three patients had periods of atrio-ventricular dissociation alternating with nodal rhythm, with a ventricular rate of between 60 and 100 (Pick and Dominguez, 1957). The remaining patient showed periods of nodal rhythm alone. The time of onset of these arrhythmias was less constant than in the supraventricular group. In two patients the arrhythmia developed and ceased spontaneously within the first four days. In the other two, however, the arrhythmia did not develop until about the end of the first week, lasting for up to three weeks in one, while in the other sinus rhythm returned on the tenth day after infarction.

In three of the four patients in this group, brachial arterial and central venous pressures were recorded during the arrhythmia. Fig. 3 shows a fall in brachial arterial pressure, with "cannon waves" in the central venous pressure record accompanying loss of atrial transport function when the normal sequential contraction of the atria and ventricles was disturbed. Although some fall in systemic blood pressure accompanied loss of atrial transport function in all patients, systolic pressure only fell below $100 \mathrm{~mm}$. $\mathrm{Hg}$ in the patient who had sustained a large, full-thickness, antero-septal cardiac infarct, which later developed into an aneurysm.

Where atrio-ventricular dissociation was present, the sino-atrial and atrio-ventricular nodes were usually found to be beating at similar rates, the sino-atrial node showing slight phasic variation due to sinus arrhythmia while the atrio-ventricular nodal rate remained constant. As a result, in a long electrocardiographic strip, the $P$ wave moved gradually forwards into the QRS complex ("flottement de l'onde P", Jouvé et al., 1954) and then retreated backwards from it again during the phasic variations in the sinus rate (Fig. 3).

Since the ventricular rate was not unduly rapid (between 60 and 100) it was decided to attempt conversion to sinus rhythm by giving intravenous atropine $(0.4-0.6 \mathrm{mg}$.). This immediately terminated atrio-ventricular dissociation in two of the patients, for with speeding up of the sino-atrial node, sinus capture of the atrio-ventricular node occurred. Since restoration of normal rhythm with return of atrial transport function resulted in a return of blood pressure to pre-existing levels, attempts were made to maintain sinus rhythm by repeated doses of atropine until it spontaneously returned.

The 61-year-old patient with a five-year history of angina, who developed an acute ventricular aneurysm and chronic left ventricular failure, was 


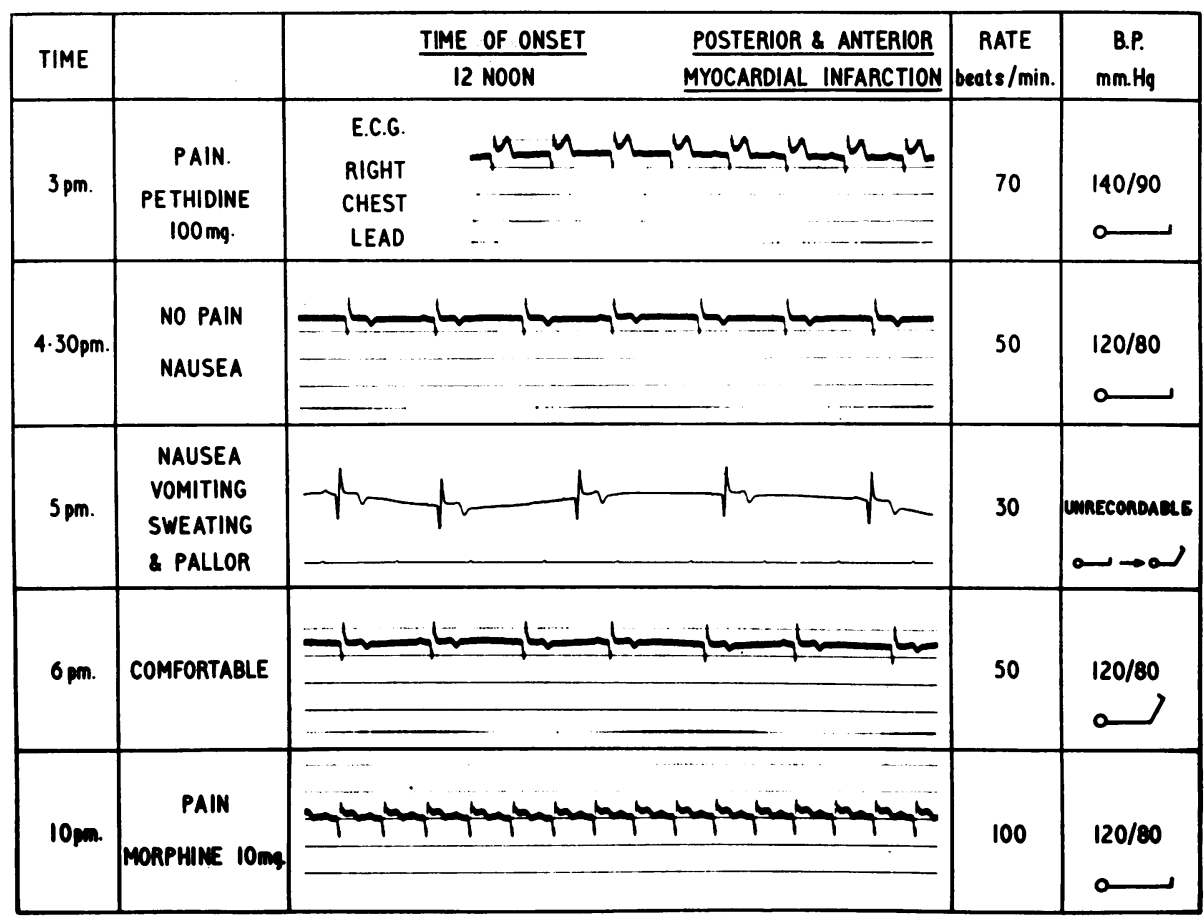

FIG. 4. Vasovagal attack in patient with acute posterior and anterior myocardial infarction, and with severe pain requiring frequent analgesics (pethidine: morphia). Electrocardiogram, right chest lead (see Fig. 1). On admission $3 \mathrm{pm}$. Pardee sign, changing to $T$ wave inversion at $4.30 \mathrm{pm}$. During vasovagal attack 5 pm., pulse slowed to 30 and blood pressure was unrecordable. Postural treatment restored blood pressure, with termination of attack.

the only patient in this group who died. Varying nodal rhythm and atrio-ventricular dissociation began on the sixth day after infarction and continued intermittently for the next four days, with the systolic blood pressure falling at times as low as $\mathbf{8 0}$ $\mathrm{mm}$. Hg. His cardiac impulse showed a sustained systolic lift over the anterior præcordium indicating the development of an anterior ventricular aneurysm. On the 26th day after infarction, 16 days after nodal rhythm had ceased, he died in chronic hypotensive heart failure. The terminal arrhythmia interrupting sinus rhythm was not recorded. At necropsy, described in detail later, a large aneurysmal antero-septal myocardial infarction was found and both main coronary arteries showed almost complete occlusion (see Fig. 11).

In summary, in the atrial transport dysfunction group, nodal rhythm or atrio-ventricular dissociation starting during the first week after the infarction was associated with a fall in blood pressure consequent on loss of atrial transport function. In three of four patients, the fall in pressure was slight, but it was more pronounced in the patient developing an aneurysm. In all four, the ar- rhythmia finally ceased spontaneously. Temporary conversion to sinus rhythm was achieved by intravenous atropine in two patients with accompanying rise of blood pressure to a normal level.

\section{SUPRAVENTRICULAR BRADYCARDIA Group (12 patients: 2 deaths)}

(a) Vasovagal Attacks. The six patients in this group had sudden episodes of bradycardia with a ventricular rate of between 30 and 50 a minute. In all six patients the systolic blood pressure fell below $100 \mathrm{~mm}$. $\mathrm{Hg}$, and in three it was recorded as low as $60 \mathrm{~mm}$. Hg. With one exception, these episodes all occurred within the first $\mathbf{4 8}$ hours, at a time when the patient was requiring frequent treatment with morphia or pethidine for relief of the severe pain accompanying the cardiac infarct. The patients were pale, sweating, nauseated, and sometimes confused mentally. The electrocardiogram showed either sinus rhythm or a wandering atrial pacemaker. The attacks had, therefore, the characteristics of vasovagal episodes (Fig. 4).

The patients in this group had certain general clin- 
ical similarities. Five had evidence of posterior infarction in the cardiogram, while in the sixth the site was unknown, the cardiogram showing left bundlebranch block. In addition, all but one showed a tendency to sinus bradycardia on admission, with heart rates of between 50 and 65 a minute. Five had suffered severe pain at the time of infarction, requiring repeated analgesics. With two exceptions, they were not in left ventricular failure.

In view of the special proneness to vasovagal attacks of patients with the syndrome of posterior infarction, sinus bradycardia, and severe cardiac pain (Table I), special watch was kept for these during the first $\mathbf{4 8}$ hours after infarction. All such patients were treated prophylactically by nursing them lying flat. When an attack developed, the foot of the bed was raised and atropine (0.4-0.6 mg.) was injected intravenously. (In addition, in one patient isoprenaline was also given.) With this treatment the pulse rapidly quickened, the blood pressure returned to its previous levels, and the patient's general condition rapidly improved.

TABLE I

ASSOCIATION OF SYNDROME OF POSTERIOR INFARCTION, SINUS BRADYCARDIA, SEVERE CARDIAC PAIN, AND FREQUENT ANALGESICS ASSOCIATED WITH VASOVAGAL ATTACKS

\begin{tabular}{c|c}
\hline No. with syndrome & $\begin{array}{c}\text { No. with associated } \\
\text { vasovagal attacks }\end{array}$ \\
\hline 8 & 4 \\
\hline
\end{tabular}

One 65-year-old patient in this group died, being the only patient in left ventricular failure. He had a seven-year history of severe ischæmic heart disease with three distinct infarctions. On this admission he developed acute renal failure, requiring peritoneal dialysis. On the fifth day during dialysis, from which he was experiencing pain requiring pethidine, he had an episode of bradycardia with a ventricular rate of 48 a minute, a blood pressure of $60 / 40 \mathrm{~mm} . \mathrm{Hg}$, and a wandering atrial pacemaker. This attack responded to the routine treatment of raising the foot of the bed and giving intravenous atropine. Both his general condition and renal function improved over the next six days but on the eleventh day after infarction he suddenly died. The rhythm at death was unknown and there was no necropsy.

In summary, episodes of sudden supraventricular bradycardia with hypotension, having the characteristics of vasovagal attacks, were met in six patients during the first 48 hours after cardiac infarction. These patients had posterior infarction; five of the six had a tendency to sinus bradycardia on admission and had had severe pain at the time of infarction requiring repeated analgesics. They, therefore, formed a clinically recognizable group in which there was a special liability to attacks. These patients responded to prompt treatment with posture and intravenous atropine.

(b) Prolonged Sinus Bradycardia. A further six patients, five of whom had posterior infarction, showed sinus bradycardia at a rate between 45 and 60 a minute, lasting for days, or even weeks, after the infarct. They did not develop vasovagal attacks, and all survived, with the exception of one who later developed a ruptured septum.

\section{VeNTRICULAR TACHYCARDIA GROUP}

(2 patients: no deaths)

In two patients in this series, paroxysmal ventricular tachycardia was the dominant arrhythmia during the first three days after infarction. Five other patients also had runs of ventricular tachycardia, but this rhythm was merely one of a number of rapidly changing agonal rhythms in these five patients who were gravely ill and in advanced congestive heart failure.

Both patients in whom ventricular tachycardia was the dominant arrhythmia during the first three days after infarction survived and made a good recovery. Their runs of ventricular tachycardia lasted up to 17 seconds. They were preceded by severe anginal pain and accompanied by palpitation. There was no accompanying faintness and the attacks were too short to allow for measurement of the blood pressure by sphygmomanometer. The first patient was a woman of 50 with a large anterior and posterior infarct, in whom the episodes were observed only on the monitoring bedside oscilloscope. In the second patient, a man of 46 with extensive anterior infarction, continuous recording on electromagnetic tape was obtained. Both were in early left heart failure.

The serial electrocardiographic changes in the second patient were studied in detail (Fig. 5). On the third day after infarction, there were frequent runs of coupled ventricular extrasystoles, followed by bursts of ventricular tachycardia. The extrasystoles were not early in time at first, but later, after a run of ventricular tachycardia, they became earlier, interrupting the $T$ wave of the previous sinus beat (Smirk and Palmer, 1960). Occasionally two consecutive ventricular extrasystoles occurred, the second extrasystole resembling the QRS configuration seen during ventricular tachycardia. In all, 


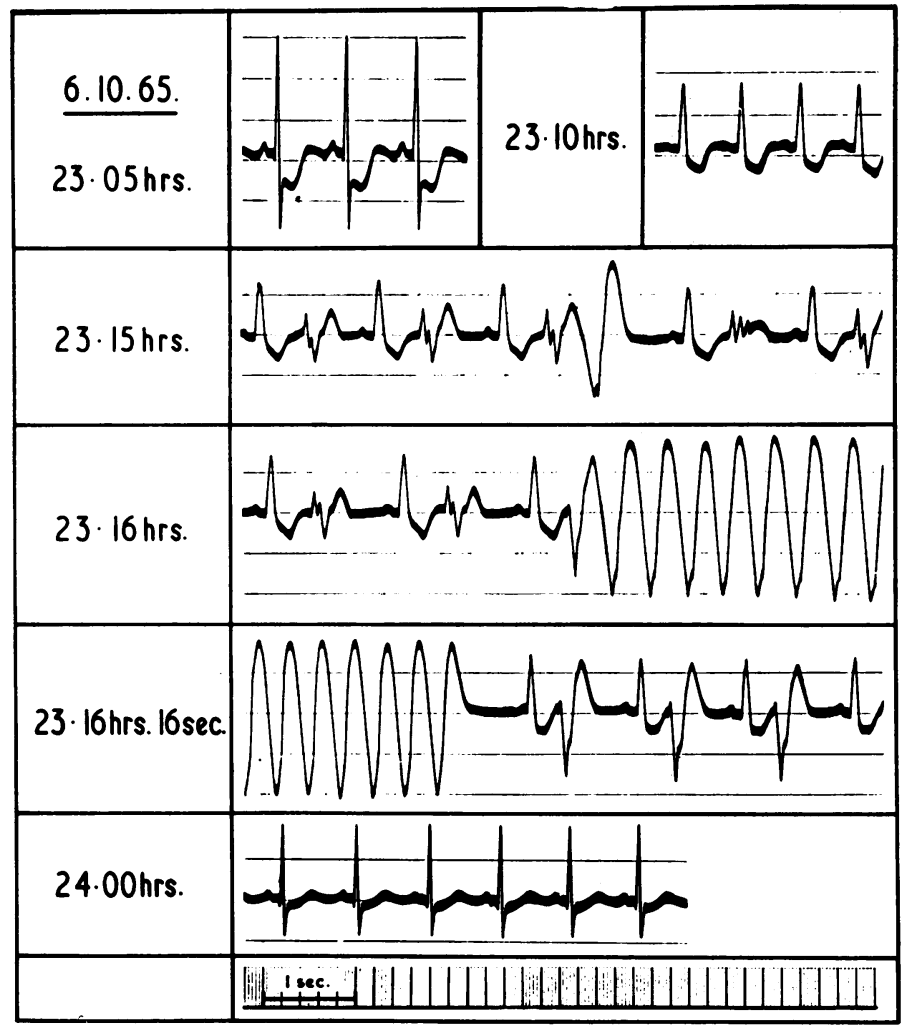

FIG. 5.-Ventricular extrasystoles preceding onset of paroxysmal ventricular tachycardia. Third day after extensive acute anterior infarction. Electrocardiogram, left chest lead (see Fig. 1). 23.05 hr., sinus rhythm; $23.10 \mathrm{hr}$., partial left bundle-branch block. $23.15 \mathrm{hr}$., coupled ventricular extrasystoles; two consecutive extrasystoles in centre, the second resembling QRS during ventricular tachycardia. $23.16 \mathrm{hr}$., coupled ventricular extrasystoles followed by ventricular tachycardia. $23.16 \mathrm{hr}$. and $16 \mathrm{sec}$., cessation of ventricular tachycardia, followed by coupled ventricular extrasystoles, with $R$ upon $T$ phenomenon. $24.00 \mathrm{hr}$., sinus rhythm with normal conduction.

this patient had three separate short episodes of ventricular tachycardia during the third day.

In view of the grave associations of these arrhythmias, propranolol therapy was given, in a dose of $80 \mathrm{mg}$. orally daily. On the following day no further ventricular tachycardia occurred, though coupled ventricular extrasystoles continued with unabated frequency. Finally on the fifth day, after a short paroxysm of atrial fibrillation, sinus rhythm returned and the patient made an uninterrupted recovery. The other patient, in whom ventricular tachycardia was observed on the oscilloscope alone, was not given propranolol, and the paroxysms of tachycardia stopped spontaneously after 24 hours.

In assessing the significance and prognosis of ventricular tachycardia in acute cardiac infarction, we feel that a clear distinction should be made between two groups. On the one hand, there are the patients in whom the general cardiovascular condition is good, who develop short runs of paroxysmal ventricular tachycardia during the first week and who often recover. On the other hand, there are those in chronic hypotensive and congestive heart failure, in whom runs of ventricular tachycardia merely form part of a varying pattern of agonal arrhythmias.

\section{VENTRICULAR BRADYCARDIA Group}

(8 patients: all died)

The eight patients in this group developed complete heart block or idio-ventricular rhythm. In four, heart block appeared merely as an agonal rhythm lasting for a few minutes, while in the other four heart block was more prolonged and associated with Stokes-Adams attacks lasting up to two days.

(a) Agonal Complete Heart Block (4 patients). Three of these four patients, aged 60,69 , and 76 years, who developed a short period of terminal heart block had been in hypotensive congestive 


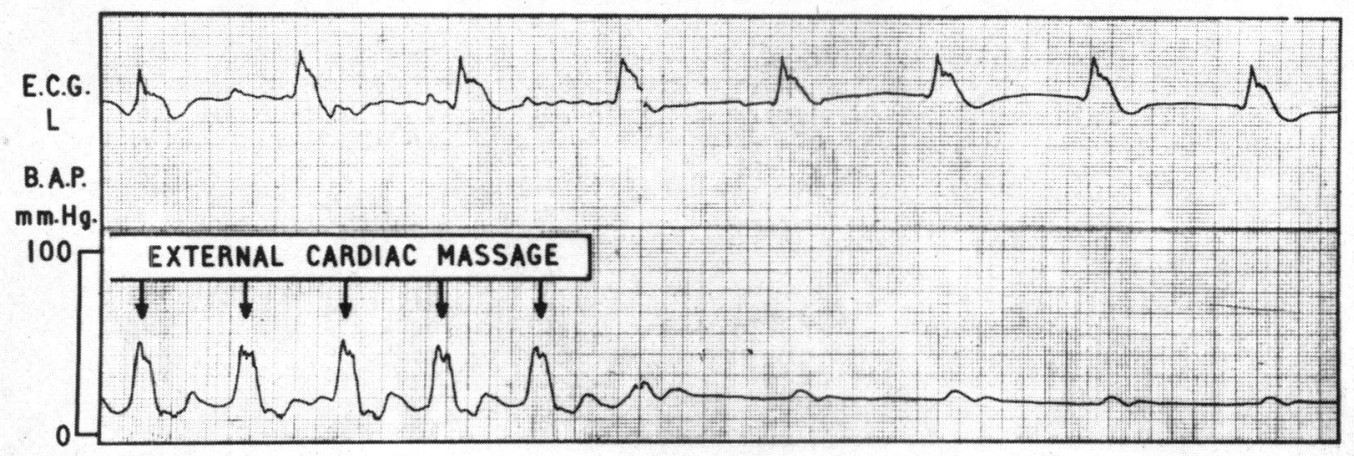

Fig. 6.-Agonal complete heart block. Simultaneous electrocardiogram, left chest lead (E.C.G.L) and brachial arterial pressure (B.A.P.). Ventricular rate $=40$. On left of tracing, brachial arterial pressure waves due to cardiac massage. On right, virtually no pressure waves, with cessation of massage, in spite of continuing electrocardiographic activity.

heart failure. At necropsy extensive postero-lateral cardiac infarction was found in one and anteroseptal infarction with septal rupture in another. The fourth patient differed in that he was aged only 36 years and was not in heart failure: necropsy revealed old posterior and recent antero-septal infarction. The nodes and bundle were examined in 2 patients and were free from evidence of infarction.

Simultaneous electrocardiograms and brachial arterial pressures were recorded continuously during the agonal period in one of the four patients, while in the other three the blood pressure was recorded with the sphygmomanometer. Virtually no evidence of effective left ventricular contraction was seen, as judged by the arterial pressure tracing, at a time when there was continued electrocardiographic activity (Fig. 6). Heart block of this type, with electrical, but little mechanical activity, lasted between five and 15 minutes and was finally followed by ventricular standstill. Three of the patients were considered too sick to warrant resuscitation. In the fourth and youngest patient, attempted resuscitation was unsuccessful.

(b) Complete Heart Block with Stokes-Adams Attacks (4 patients). In contrast to the agonal group in which no significant mechanical systole accompanied complete heart block, the patients with Stokes-Adams attacks still had adequately functioning hearts, though with some reduction in blood pressure. Complete heart block lasted for 24 to 48 hours. The Stokes-Adams attacks were associated with periods of ventricular standstill. The ages of the four patients lay between 58 and 72 years. Three had a previous history. of ischæmic heart disease, in one going back as long as 13 years, and three were in left ventricular failure. Necropsies in three patients revealed extensive infarction: in two of them the nodes and bundle were examined and no evidence of infarction found.

Simultaneous central venous and brachial arterial records accompanying the electrocardiogram were obtained in two patients: one showed an initial fall in blood pressure with the onset of heart block (Fig. 7); in the other there was a tendency to further pressure falls after each successive period of ventricular standstill (Fig. 8).

Treatment by endocardial pacing was attempted in three patients, but was unsuccessful in two. In a third patient pacing for one hour tided him over a period of recurring Stokes-Adams attacks, with return of sinus rhythm; unfortunately, however, he had a further arrhythmia two days later, with terminal ventricular fibrillation, from which he died. In retrospect, the pacemaker should have been left in longer. In the fourth patient ventricular tachycardia developed within two hours of the patient's transfer from another hospital, culminating within a matter of minutes in ventricular fibrillation and death. He had been treated with isoprenaline and steroids for two days before arrival and we feel that the prolonged isoprenaline treatment may have been partly responsible for the ventricular tachycardia. Steroids (hydrocortisone $100 \mathrm{mg}$. intravenously and prednisone $10 \mathrm{mg}$. six hourly) were given to all these patients empirically.

In summary, complete heart block occurred either as an agonal rhythm in a dying heart, or as a more prolonged arrhythmia associated with StokesAdams attacks. It so happened that it carried a uniformly fatal prognosis in the eight patients in this reported series, though further cases treated in this unit have had a favourable outcome. 


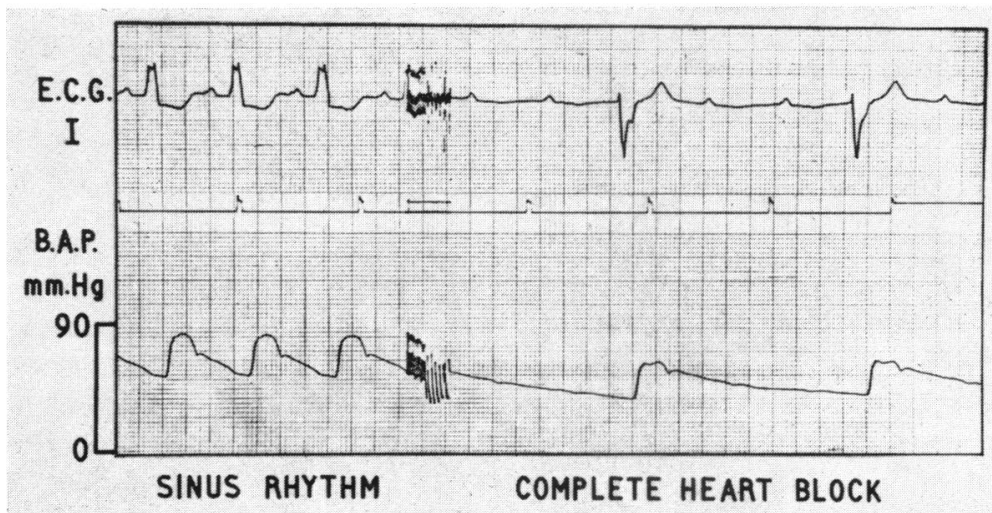

FIG. 7.-Fall in brachial arterial pressure (B.A.P.) with onset of complete heart block. Electrocardiogram, standard lead I (E.C.G.I). Heart rate fell from 85 to 30 with simultaneous fall in blood pressure from 80/50 to $60 / 35 \mathrm{~mm}$. $\mathrm{Hg}$.

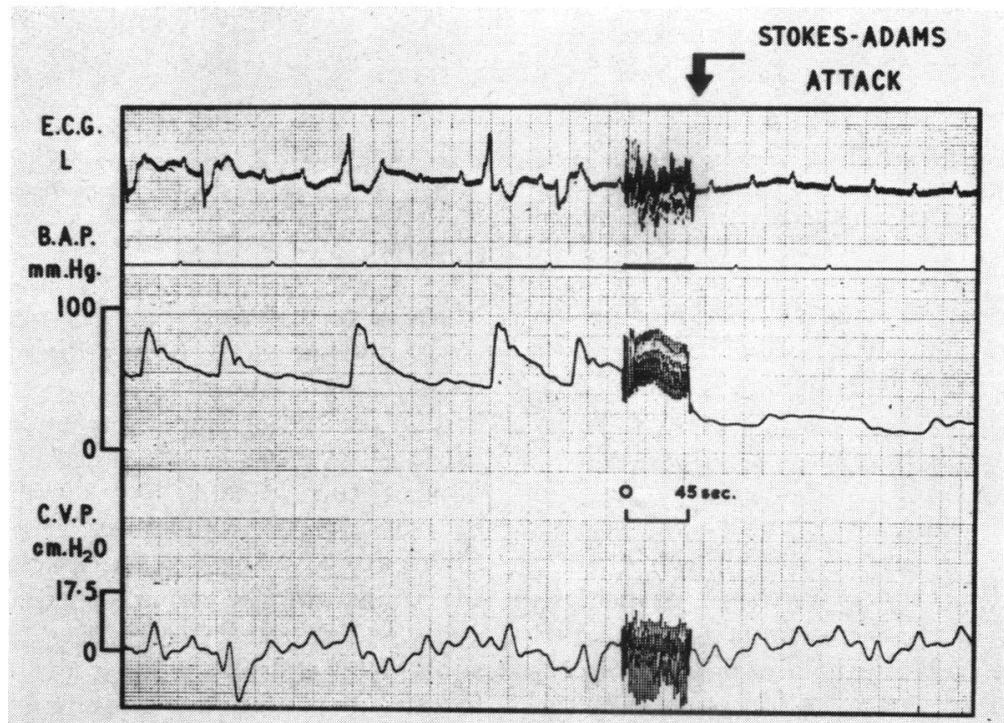

FIG. 8.-Stokes-Adams attack. Complete heart block, followed by ventricular standstill. Simultaneous electrocardiogram, left chest lead (E.C.G.L), brachial arterial pressure (B.A.P.), and central venous pressure (C.V.P.). Changing ventricular pacemaker focus during heart block immediately before arrest.

\section{SINUS RHYTHM OR EXTRASYSTOLES ONLY (17 patients: no deaths)}

(a) Sinus Rhythm. Seven of the patients in the series showed no arrhythmias. All made a good recovery, though one was in early left ventricular failure. Five patients had an anterior infarct and two a combined antero-posterior infarct.

(b) Extrasystoles Alone. Ten patients had extrasystoles as the sole arrhythmia and all did well. In seven the infarct was anterior; in two combined antero-posterior; and in one the site was uncertain, owing to previous infarcts.

\section{Extrasystoles Immediately Preceding More Serious Arrhythmias}

(a) Onset of Atrial Fibrillation. Of the seven patients in this series with dominant atrial fibrillation after admission to hospital, the moment of onset of atrial fibrillation was recorded on the electromagnetic tape in six. Of these six patients, two showed coupled atrial ectopic beats immediately 

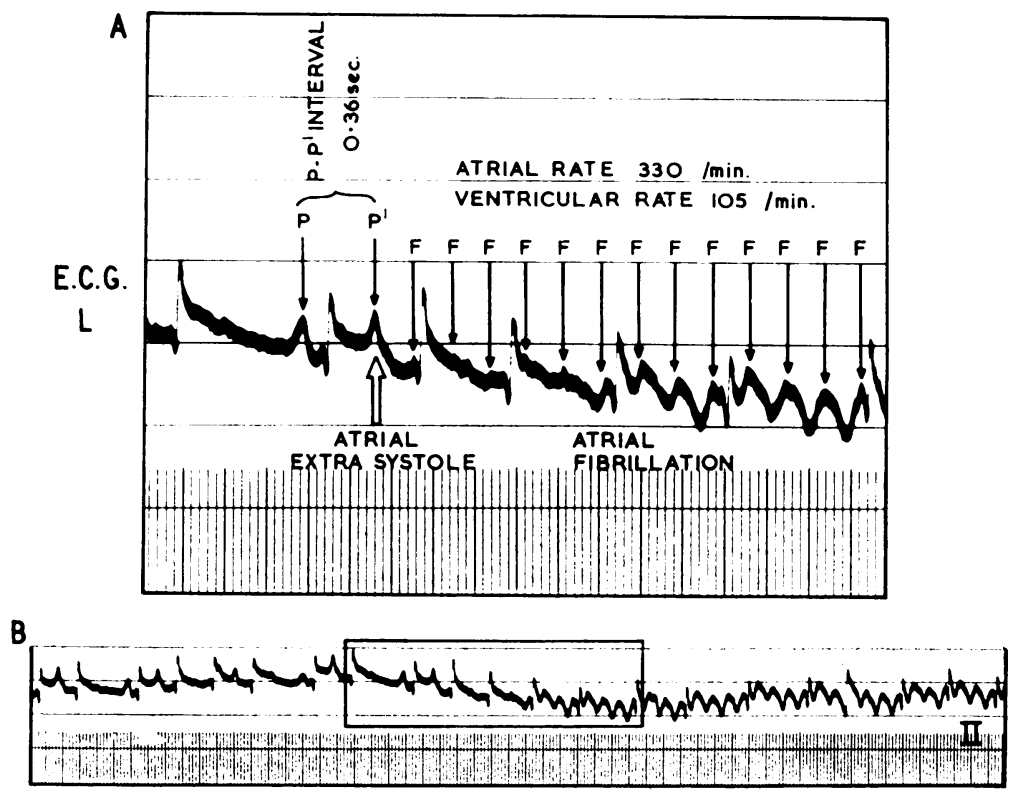

FIG. 9.--Coupled atrial extrasystoles preceding onset of atrial fibrillation. Electrocardiogram, left chest lead (E.C.G. L). $\quad A=$ enlargement of central boxed portion of $B$. In $A$, sinus $P$ wave $(P)$ is followed by extrasystolic $P$ wave $\left(P^{\prime}\right) \quad 0.36$ sec. later. Immediately after this $F$ waves of atrial fibrillation begin, small at first, rapidly enlarging.

preceding the onset of atrial fibrillation (Fig. 9), while in the remaining four, a normal sinus beat was immediately followed by fibrillation.

In the two patients with coupled atrial extrasystoles preceding fibrillation the arrhythmia was of the flutter-fibrillation type, with regular but varying atrial $F$ wave rates, between 300 and 400 a minute, but an irregular ventricular rate. The preceding coupled atrial extrasystoles were not particularly early in relation to the previous sinus beat, the $\mathrm{P}-\mathrm{P}^{\prime}$ interval being $0.36 \mathrm{sec}$. in one and $0.48 \mathrm{sec}$. in the other. The final extrasystole introducing flutterfibrillation did not differ in any respect from the preceding runs of coupled atrial ectopic beats. Both patients had more than one paroxysm of atrial fibrillation; on each occasion the same sequence was repeated, frequent coupled atrial extrasystoles being followed by atrial fibrillation.

The mechanism underlying the sequential development of atrial extrasystoles and atrial flutterfibrillation is probably complex, though the concept of the atria shocking themselves into fibrillation during their vulnerable period appears attractive at first sight. This, however, leaves unexplained the cause of the frequent extrasystoles, and also the unusual vulnerability of the atria to a stimulus that in a healthy heart would be unlikely to produce fibrillation. It seems more likely that shortening of the refractory period may be responsible for both these phenomena. Myocardial anoxia and increased vagal tone may both occur in acute myocardial infarction, and these factors are known to cause shortening of the atrial refractory period. This in turn facilitates the development of atrial fibrillation (Webb and Hollander, 1956; Burn, 1960). Shortening of the refractory period also affects the timing of the supernormal period (Burchell, 1963), when extrasystoles may be provoked by a subliminal stimulus. It seems likely, therefore, in this way that an underlying change in the refractory period is responsible both for extrasystoles and flutter-fibrillation in these patients with acute cardiac infarction.

(b) Onset of Ventricular Tachycardia. Of the seven patients who developed runs of ventricular tachycardia, the moment of onset of tachycardia was recorded on the electromagnetic tape in four. Of these four, three had frequent coupled ventricular ectopic beats immediately preceding the onset of ventricular tachycardia, while in the remaining patient, bursts of ventricular tachycardia interrupted complete heart block.

The prodromal pattern of ventricular extrasystoles preceding ventricular tachycardia varied. Only one of the three patients showed unusually 
early extrasystoles, interrupting the $\mathrm{T}$ wave of the previous sinus beat (Smirk and Palmer, 1960), while in the other two patients, the ventricular extrasystoles fell clear of the $T$ wave. A constant prodromal sign in our three patients was the occurrence of two successive ventricular extrasystoles, the second showing marked ST segment shift. This second extrasystole resembled the QRST complex seen later in the sinus of ventricular tachycardia (Fig. 5). In this way the ventricular tachycardia appeared to show a stuttering onset.

It seems likely that a similar mechanism operates in the ventricles, in the development of ventricular tachycardia, as operates in the atria, with atrial flutter-fibrillation. The myocardial ischæmia causes shortening of the ventricular refractory period. As a result of the shortened refractory period, both ventricular extrasystoles and ventricular tachycardia are facilitated.

\section{General Factors Influencing Prognosis}

It is well known that certain general factors, including age, heart failure, associated hypotension, and the length of history of ischæmic heart disease, influence the prognosis in acute cardiac infarction (McMichael and Parry, 1960; Peel et al., 1962). The expected correlation with such factors was found in our series of 50 patients (Table II). Thus,

TABLE II

INFLUENCE OF ADVERSE FACTORS ON PROGNOSIS OF ARRHYTHMIAS WITH INFARCTION

\begin{tabular}{|c|c|c|}
\hline & Died & Survived \\
\hline Number of patients & $12\} \begin{array}{l}10 \text { men } \\
2 \text { women }\end{array}$ & 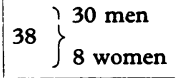 \\
\hline $\begin{array}{l}\text { Average age (yr.) } \\
\text { Hypertension } \\
\text { Left ventricular failure } \\
\text { Average duration of ischæmic } \\
\text { heart disease (yr.) } \\
\text { Left bundle-branch block } \\
\text { LDH enzymes }\end{array}$ & $\begin{array}{c}64 \\
6 \\
10 \\
3 \\
5 \\
679 \text { i.u. } \\
\text { Heat-stable } 72\end{array}$ & $\begin{array}{c}56 \\
6 \\
11 \\
1 \\
1 \\
465 \text { i.u. } \\
\text { Heat-stable } 71 \%\end{array}$ \\
\hline
\end{tabular}

the average age of those who died was higher (64 years) than of those who survived (56 years). Left ventricular failure was present in 10 of the 12 patients who died, but in only 11 of the 38 who survived. Six of the 12 fatal cases were hypertensive, compared with only six out of the 38 surviving. The average length of the history of ischæmic heart disease was over three years in those who died, but only one year in those who survived. A correlation was also noted between the height of the lactic dehydrogenase enzyme estimation and a fatal outcome, those who died having an average level of 679 i.u. (72\% heat-stable) as against 465 i.u. (71\% heat-stable) in those who survived. Of interest also was the poor prognosis carried by left bundlebranch block, five of the 12 patients who died having left bundle-branch block, as against only one of those who survived.

While, therefore, the onset of an arrhythmia in our series was itself an adverse factor, serious arrhythmias developed more frequently in the group of patients generally recognized as poor risk cases. In only one instance did it appear that the chance occurrence of an arrhythmia after acute infarction in a young patient, not in heart failure, with a normal blood pressure and a relatively short history of ischæmic heart disease, itself determined the fatal outcome in an otherwise relatively good risk patient.

\section{NECROPSY FindingS IN RELATION TO THE DOMINANT ARRHYTHMIA}

Necropsies were obtained in nine patients in this series: in six the coronary arteries were injected after death and, in addition, in seven, careful study was made of the pacemaker nodes and the atrioventricular bundle. The findings are summarized in Table III, and discussed according to the predominant arrhythmia during the terminal infarction.

Atrial Fibrillation (1 case) (Patient H.R.). This 62-year-old hypertensive patient had paroxysmal atrial flutter-fibrillation during the first four days after cardiac infarction. She died two months later in chronic heart failure. The heart was of increased weight at necropsy $(435 \mathrm{~g}$.). There was a fibrous antero-septal infarct of two months' duration, with some aneurysmal dilatation. No atrial infarction was seen. Coronary injection showed irregular narrowing in both vessels with severe narrowing in one portion of the anterior descending branch of the left coronary artery. The sino-atrial node was supplied by an apparently normal branch from each coronary artery. The sino-atrial node itself was largely replaced by adipose and fibrous tissue, but a few remaining strands of nodal tissue were seen close to the artery (Fig. 10). The atrio-ventricular node and bundle were within normal limits.

It is doubtful how much significance can be attached to the partial replacement of the sino-atrial node by adipose and fibrous tissue in the 62-year-old patient with paroxysmal atrial fibrillation, since similar histological changes may be met in controls of the same age.

Atrio-ventricular Dissocation and Nodal Rhythm (1 case) (Patient S.). This 61-year-old patient had paroxysmal atrio-ventricular rhythms between the sixth and tenth day after infarction. He died a fortnight later in chronic heart failure with signs of a ventricular aneurysm. At necropsy there was biventricular hypertrophy, the heart weighing $570 \mathrm{~g}$. There was an antero-septal infarct of three weeks' duration, with apical aneurysmal dilatation and myocardial thinning. 


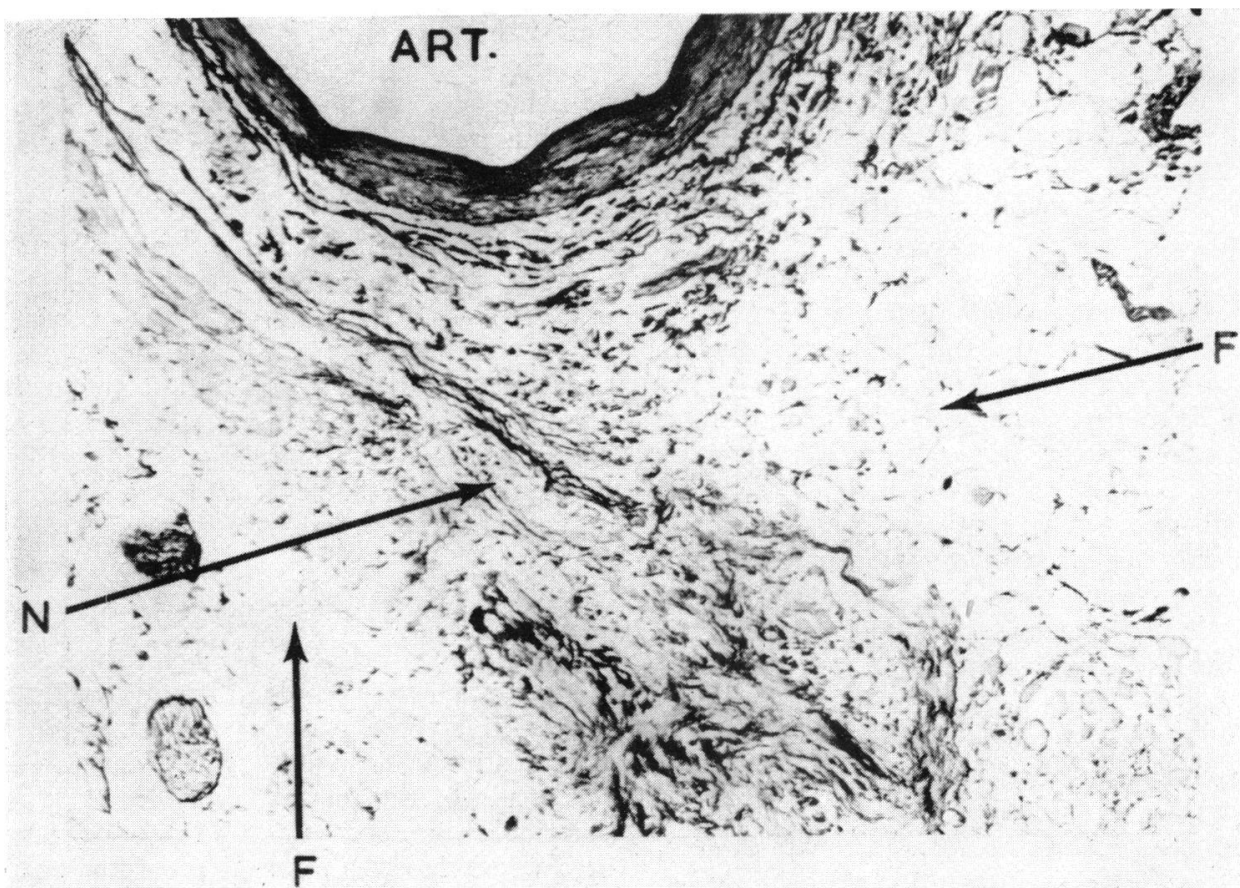

FIG. 10.-Sino-atrial node, in patient with paroxysmal atrial fibrillation. Some nodal tissue seen (N), but node partly replaced by adipose and fibrous tissue $(F)$, within normal limits for age 61 years. Part of the artery to the node shown (ART). (Elastic-van Gieson. $\times 85$.)

There was no atrial infarction. The injected coronary node arose in front of the site of occlusion in the right arteries showed almost complete occlusion of both main branches in two places. The artery to the sino-atrial coronary artery and appeared normal (Fig. 11). There was marked avascularity in the region of the aneurysm.

TABLE III

FINDINGS AT NECROPSY IN NINE PATIENTS DYING WITH ARRHYTHMIA IN CARDIAC INFARCTION

\begin{tabular}{|c|c|c|c|c|c|c|c|c|c|c|c|c|}
\hline \multirow{2}{*}{\multicolumn{2}{|c|}{$\begin{array}{l}\text { Patient, age, } \\
\text { and sex }\end{array}$}} & \multirow[b]{2}{*}{$\begin{array}{c}\text { Dominant } \\
\text { arrhythmia }\end{array}$} & \multirow[b]{2}{*}{$\begin{array}{l}\text { Heart } \\
\text { weight } \\
\text { (g.) }\end{array}$} & \multicolumn{2}{|c|}{ Infarct } & \multicolumn{3}{|c|}{ Coronary arteries } & \multirow[b]{2}{*}{$\begin{array}{l}\text { Artery } \\
\text { to S-A } \\
\text { node }\end{array}$} & \multicolumn{3}{|c|}{$\begin{array}{c}\text { Nodes and conducting } \\
\text { bundle }\end{array}$} \\
\hline & & & & Site & Age & Right & $\begin{array}{l}\text { Left an- } \\
\text { terior de- } \\
\text { scending }\end{array}$ & Circ. & & $\begin{array}{c}\text { S-A } \\
\text { node }\end{array}$ & $\begin{array}{l}\text { A-V } \\
\text { node }\end{array}$ & $\begin{array}{c}\mathrm{A}-\mathrm{V} \\
\text { bundle }\end{array}$ \\
\hline & $62 \mathrm{~F}$ & Atrial fibrill- & 435 & Antero-septal & $2 \mathrm{mth}$. & $\mathbf{S}(+)$ & $\mathbf{S}(++)$ & $\mathbf{S}(+)$ & $\mathbf{N}$ & Fibrous & $\mathbf{N}$ & $\mathbf{N}$ \\
\hline $\mathbf{S}$ & $61 \mathrm{M}$ & $\begin{array}{l}\text { ation } \\
\text { A-V rhythm }\end{array}$ & 570 & $\begin{array}{l}\text { (aneurysm) } \\
\text { Antero-septal }\end{array}$ & 3 wk. & $S(+++)$ & $\mathbf{s}(+++)$ & $\mathbf{S}(+++)$ & $\mathbf{N}$ & Fibrous & $\mathbf{N}$ & $\mathbf{N}$ \\
\hline F & $74 \mathrm{M}$ & $\begin{array}{l}\text { Agonal } \\
\text { ventricular } \\
\text { tachycardia }\end{array}$ & 515 & $\begin{array}{l}\text { (aneurysm) } \\
\text { Antero-septal } \\
\text { (ruptured }\end{array}$ & $10 \mathrm{dy}$. & $\mathbf{S}(+)$ & B & $\mathbf{S}(+)$ & $\mathbf{N}$ & $\mathbf{N}$ & $\mathbf{N}$ & $\mathbf{N}$ \\
\hline v & $76 \mathrm{M}$ & $\begin{array}{c}\text { Complete } \\
\text { heart block }\end{array}$ & 507 & $\begin{array}{l}\text { Antero-septal } \\
\text { (ruptured }\end{array}$ & $4 \mathrm{dy}$. & & \multicolumn{2}{|c|}{ Extensive atheroma } & & & & \\
\hline A & $60 \mathrm{M}$ & $\begin{array}{l}\text { Complete } \\
\text { heart block }\end{array}$ & 430 & Postero-lateral & $\begin{array}{l}1 \text { wk. and } \\
\text { more }\end{array}$ & $\mathbf{S}(+++)$ & B & $\mathbf{S}(+)$ & $\mathrm{N}$ & Fibrous & $\mathbf{N}$ & Fibrous \\
\hline $\mathbf{L}$ & $36 \mathrm{M}$ & $\begin{array}{l}\text { Complete } \\
\text { heart block }\end{array}$ & 380 & $\begin{array}{l}\text { Old and recent } \\
\text { posterior, } \\
\text { recent antero- } \\
\text { septal }\end{array}$ & $\begin{array}{l}6 \text { mth. }+ \\
\text { and } 2 \text { wk. } \\
1 \text { wk. }\end{array}$ & $\mathbf{S}(++)$ & B & $\mathbf{S}(++)$ & $\mathbf{N}$ & $\mathbf{N}$ & $\mathbf{N}$ & Fibrous \\
\hline $\mathbf{R}$ & $67 \mathrm{M}$ & $\begin{array}{l}\text { Complete } \\
\text { heart block }\end{array}$ & 595 & $\begin{array}{l}\text { Old posterior, } \\
\text { recent antero- }\end{array}$ & $\begin{array}{l}4 \text { mth. } 4 \\
\text { dy. }\end{array}$ & & \multicolumn{2}{|c|}{$\begin{array}{l}\text { Extensive atheroma; } \\
\text { multiple occlusions }\end{array}$} & & & & \\
\hline Go & $67 \mathrm{~F}$ & $\begin{array}{l}\text { Complete } \\
\text { heart block }\end{array}$ & 620 & $\begin{array}{l}\text { Old posterior, } \\
\text { recent antero- }\end{array}$ & 6 mth. 2 & $\mathbf{s}(+++)$ & $\mathbf{s}(+++)$ & $\mathbf{S}(++)$ & $\mathbf{S}(+)$ & $\mathrm{N}$ & $\mathbf{N}$ & $\mathbf{N}$ \\
\hline Gi & $72 \mathrm{M}$ & $\begin{array}{l}\text { Complete } \\
\text { heart block }\end{array}$ & 500 & $\begin{array}{l}\text { Septal } \\
\text { Old posterior, } \\
\text { recent antero- } \\
\text { septal }\end{array}$ & $\begin{array}{l}2 \text { mth. }+1 \\
\text { dy. }\end{array}$ & B & $\mathbf{S}(+++)$ & $\mathbf{S}(+)$ & $\mathbf{N}$ & $\mathbf{N}$ & $\mathbf{N}$ & $\begin{array}{c}\text { Few } \\
\text { neutrophils }\end{array}$ \\
\hline
\end{tabular}




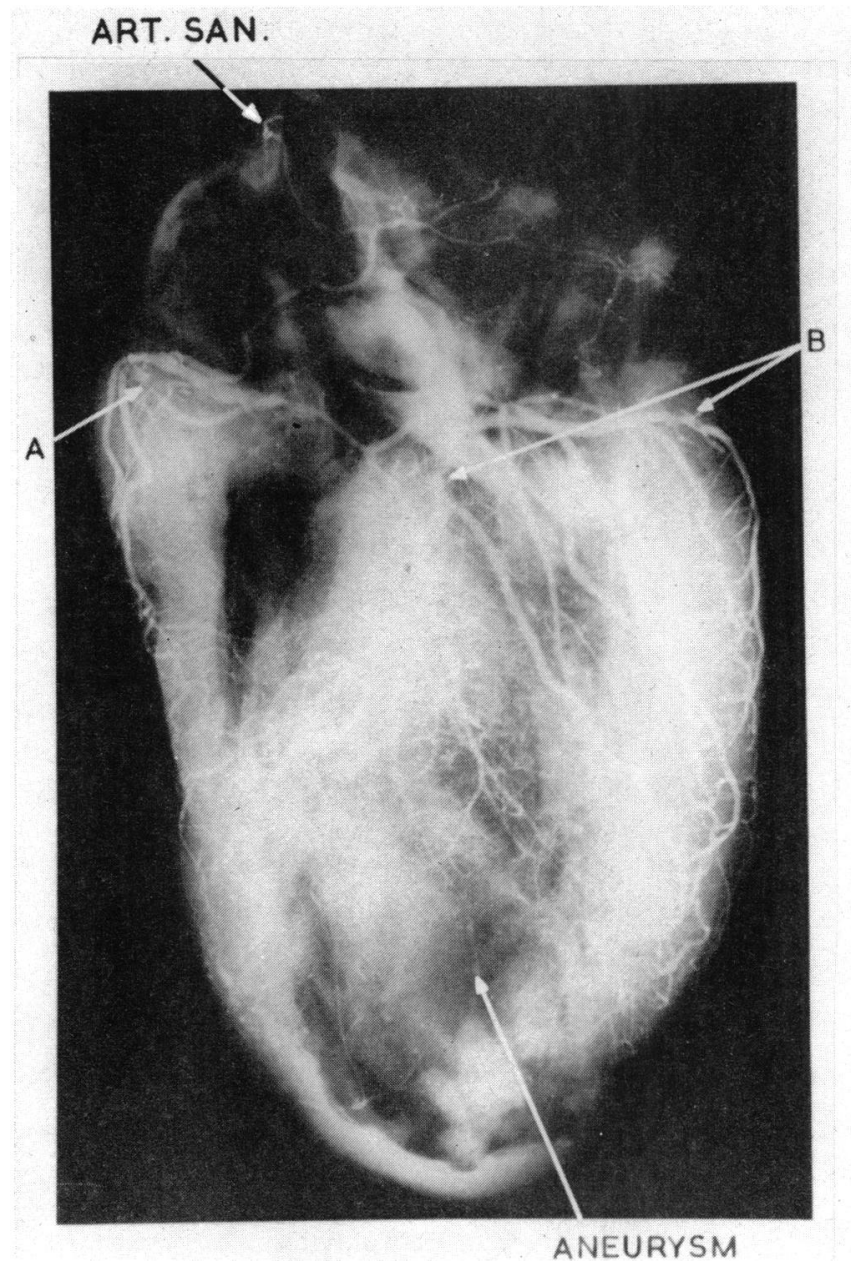

FIG. 11.-Post-mortem coronary arteriogram in patient with A-V dissociation. Artery to S-A node patent (ART. SAN). Almost total occlusion of right coronary artery (A), which continues with greatly narrowed lumen. Severe narrowing of left circumflex and anterior descending branches of left coronary artery (B). No vascularity in region of aneurysm and greatly thinned neighbouring vessels.

The sino-atrial node showed slight increase in fibroelastic tissue (Fig. 12), while the atrio-ventricular node and bundle appeared normal.

Since the amount of fibrosis seen in the sino-atrial node was not more than might be seen in a control of the same age, there was no evidence that this was responsible for the paroxysmal atrio-ventricular dissociation and rhythm during the first 10 days after infarction.

Agonal Ventricular Tachycardia (1 case) (Patient F.). This 74-year-old patient died with a ruptured ventricular septum and congestive heart failure a week after the onset of infarction, his agonal rhythm being ventricular tachycardia. Necropsy confirmed the presence of antero-septal infarction with septal rupture $3 \mathrm{~cm}$. from the apex. Coronary injection showed complete occlusion of the anterior descending coronary artery, with, in addition, irregular narrowing of the left circumflex and the right coronary artery. No abnormality was found in the sino-atrial or atrio-ventricular nodes or the atrioventricular bundle.

Complete Heart Block (6 cases). Three of the patients (aged 72, 67, and 67) developed paroxysmal complete heart block during the first week after cardiac infarction, associated with Stokes-Adams attacks. In the remaining three (aged 76, 60, and 36) complete heart block was seen as a short agonal rhythm. Four were found to have an old posterior cardiac infarct, with, in addition, recent antero-septal infarction. In the remaining two, recent extensive infarction was found, involving in one case the antero-septal and in the other the postero-lateral region. There was extensive coronary atheroma involving both right and left coronary arteries and widespread occlusions in all six patients (Table III). Special study of 


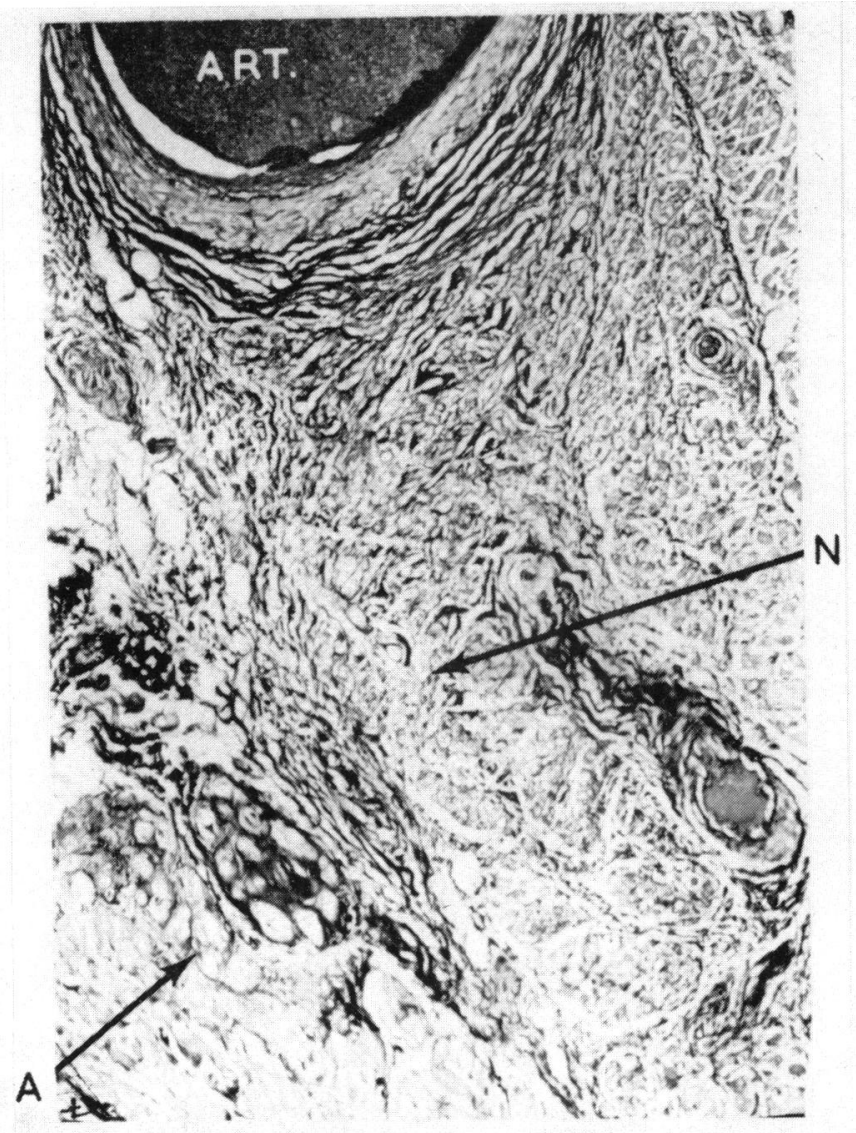

FIG. 12.-Sino-atrial node in same patient as Fig. 11. Slight increase in elastic and collagen fibres, normal for a man aged 66 . Nodal muscle fibres $(\mathrm{N})$ paler and finer than atrial muscle fibres (A). The artery to the node (ART.) filled with injection material. (Elastic-van Gieson. $\times 82$. )

the nodes and conducting bundle in four patients showed no evidence of infarction of these structures. Some fibro-fatty replacement of the atrio-ventricular bundle was seen in two patients, with slight fibrosis of the sinoatrial node in one. Another patient showed a few neutrophils within the bundle.

In summary, in six patients with paroxysmal complete heart block after acute myocardial infarction, coronary arterial disease was always widespread and severe. The recent infarct was anterior in five and posterior in one, with, in addition, old posterior infarction in four. The atrio-ventricular bundle and the atrio-ventricular node, however, did not show evidence of frank infarction though there were minor degrees of fibro-fatty replacement.

\section{Discussion}

Arrhythmias were found in 80 per cent of our patients, who had been continuously monitored during the first ten days after cardiac infarction.
In previous studies with routine electrocardiography the incidence of arrhythmias had been found to be as low as 14 per cent (Master et al., 1937), but the high incidence in our series parallels that now being found with continuous monitoring in other centres (Robinson, Sloman, and McRae, 1964; Julian et al., 1964).

The arrhythmias after acute cardiac infarction were found to be often transient and rapidly changing. Many would have been missed without the aid of continuous monitoring. Most arrhythmias started within the first two days and had stopped by the tenth day. Vasovagal attacks, when these occurred, were restricted to the first 48 hours after infarction. A sudden unexpected fatal arrhythmia without other prodromal rhythm disturbances was only met in one patient.

We have proposed a broad working classification of the arrhythmias in acute cardiac infarction, based 
on the over-all cardiac response to the dominant arrhythmia:- (1) supraventricular tachycardia (atrial tachycardia, flutter, and fibrillation, grouped together as these rhythms were frequently intermixed); (2) supraventricular bradycardia (sinus bradycardia often associated with vasovagal attacks); (3) atrial transport dysfunction, with varying nodal rhythm or atrio-ventricular dissociation; (4) ventricular tachycardia; (5) ventricular bradycardia, with various forms of heart block and idio-ventricular rhythm; (6) sinus rhythm or extrasystoles only.

The site of the infarct was to some extent related to the type of arrhythmia seen. Thus, all patients in the supraventricular tachycardia group had an anterior infarct, an association previously noted by Rosenbaum and Levine (1941), though Askey and Neurath (1945) failed to confirm this.

In our patients with nodal rhythm or atrioventricular dissociation the site of the infarct varied, though Pick and Dominguez (1957) and Julian et al. (1964) found an association with posterior cardiac infarction. We believe that autonomic imbalance, with relative increase in vagal tone, probably played a part in the genesis of atrio-ventricular rhythm and dissociation in our patients, since we were able to restore sinus rhythm by giving intravenous atropine.

A more constant association was found between posterior cardiac infarction and bradycardia, either of supraventricular or ventricular type. All but two of our patients with supraventricular bradycardia had a posterior infarct, which was often of only small size. This association had previously been noted by Imperial, Carballo, and Zimmerman (1960); James (1961); and Julian et al. (1964). Similarly, all but one of our patients developing complete heart block had posterior infarction, though in contrast to those with supraventricular bradycardia, these patients usually had multiple sites of infarction often with recent anterior superimposed on old posterior involvement. The association between posterior infarction and complete heart block is well recognized (Master, Dack, and Jaffe, 1938; Woods and Barnes, 1942; Mintz and Katz, 1947; Smith, Keyes, and Denham, 1951; Penton, Miller, and Levine, 1956; Condry and Thompson, 1957; Gilchrist, 1958; Imperial et al., 1960; Beard et al., 1960; Courter, Moffat, and Fowler, 1963; Julian et al., 1964).

Histology of the Nodes and Bundle. The relatively normal histology of the pacemaker nodes and atrioventricular bundle in the seven patients in whom detailed studies of these were made, accords well with the essentially transient and changing nature of the arrhythmias in our series of patients.
In the patient with paroxysmal atrial fibrillation, the artery to the sino-atrial node was found to be patent, though partial replacement of the sinoatrial node was seen. The significance of this fibrosis in the node was doubtful, in that a comparable amount of fibrosis was seen in controls of the same age-group. Our negative findings in this single case differ from James' series (1961) in which he found occlusion of the artery to the sinoatrial node and infarction of the node in patients developing atrial arrhythmias after cardiacinfarction.

Similarly, no evidence of infarction of the atrioventricular node or bundle was seen in four patients with complete heart block, though some fibrous replacement of the bundle was noted in two and infiltration with a few neutrophils in a third. The amount of fibrous replacement was within normal limits for patients of this age-group. In our series, therefore, temporary impairment of the circulation to the atrio-ventricular conducting tissues, without infarction of these tissues, as described by Blondeau, Rizzon, and Lenègre (1961), seems likely to have been the cause of the complete heart block.

Circulatory Changes Accompanying Arrhythmias. Cardiac catheterization, using a PE60 floating catheter, and direct arterial blood pressure recording provided more detailed understanding of the circulatory changes accompanying the arrhythmias. Short paroxysms of rapid atrial flutter-fibrillation in one patient caused little change in pulmonary arterial and right ventricular end-diast.jlic pressures. This single observation was in line with our over-all clinical impression that patients tolerated short bursts of atrial fibrillation relatively well. Of special interest were the right atrial and brachial arterial pressures in patients with paroxysmal nodal rhythm or atrio-ventricular dissociation. In these patients with recent cardiac infarction, loss of atrial transport function resulted in a conspicuous fall in systemic blood pressure, with probable fall in stroke output. Similar pressure variations were observed by Braunwald and Frahm (1961) in atrioventricular dissociation in aortic stenosis, and also by Samet et al. (1963) in cardiac pacing in patients with complete heart block.

In complete heart block, different degrees of hæmodynamic disturbance were observed in our series. In some the blood pressure was well maintained, but in others a fall of pressure occurred with the onset of heart block, the heart failing to increase its stroke output sufficiently to compensate for the bradycardia. In dying patients with agonal complete heart block virtually no pulse pressure accompanied continuing electrical activity in the electrocardiogram. 
Treatment of the arrhythmias was guided in most cases primarily by the circulatory state, as the arrhythmias were often transient. We also tried to avoid, as far as possible, any drug that might itself introduce other complicating arrhythmias. In the treatment of heart failure, diuretics with salt restriction formed the mainstay of therapy. Digitalis was used sparingly, because of its known arrhythmogenic properties. Continuous oxygen in a 30 to $\mathbf{4 0}$ per cent mixture by mask was helpful in raising the slightly lowered partial pressure of oxygen in some of these patients. We routinely nursed patients lying flat, thus to some extent maintaining their blood pressure by postural means alone, without the use of vasoconstrictor drugs, with their possible peripheral, ischæmic, and arrhythmogenic complications.

In the treatment of rapid supraventricular tachycardia, including atrial fibrillation, we rarely found it necessary to use digitalis, unless a prolonged rapid bout of atrial fibrillation occurred. As already described, these arrhythmias were paroxysmal, usually short-lived, and relatively well tolerated, and they terminated spontaneously in all patients. We never had to use quinidine or procaine amide.

In treating supraventricular bradycardia, rapid measures to cut short a vasovagal attack often heralded by nausea and vomiting were of importance. We noted a syndrome consisting of posterior cardiac infarction, a tendency to sinus bradycardia, and repeated attacks of chest pain requiring analgesics, and found that this was often followed by one or more vasovagal attacks within the first $\mathbf{4 8}$ hours. By keeping special watch on these patients, it was possible to combat the vasovagal attack immediately, raising the foot of the bed and giving intravenous atropine. Intravenous atropine has been advocated by others in the treatment of posterior cardiac infarction with bradycardia (James, 1962; Hellerstein and Turell, 1964).

A fall in systemic blood pressure accompanied the onset of nodal rhythm or atrio-ventricular dissociation in our patients, none of whom had a rapid ventricular rate. We therefore attempted to restore and maintain sinus rhythm by repeated doses of intravenous atropine. The blood pressure rose to its previous levels on restoration of sinus rhythm. Julian et al. (1964) found this rhythm in 8 per cent of their patients with cardiac infarction, but considered it of little clinical importance.

Our limited experience with ventricular tachycardia, in patients whose general condition was good, did not enable us to form definite views about treatment. In one of our two patients, propranolol was given, and this may have helped to prevent a recurrence of ventricular tachycardia and to abolish coupled ventricular extrasystoles.

Our results in the treatment of complete heart block after acute infarction were disappointing. We believe that pacing of the heart is indicated in these patients if a resulting inadequate cardiac output or Stokes-Adams attacks supervene, and that an internal pacing catheter should not be removed prematurely. It has been our practice to give steroids on an empirical basis. We have also given isoprenaline, but feel that this drug predisposes to various other types of complicating arrhythmias, such as paroxysmal supraventricular or ventricular tachycardia.

Prognosis in Relation to General Clinical Picture. Assessment of the prognosis of the arrhythmias after acute cardiac infarction can only usefully be made in relation to the clinical picture as a whole. We feel that the patient's age, associated diseases, such as hypertension or diabetes, the length of the history of ischæmic heart disease, the number of previous infarcts and their extent, the size of the heart, and the presence of heart failure, must all be given due weight in assessing the outcome in the individual patient. The occurrence of the same arrhythmia in different patients and under different circumstances will carry a different prognosis.

Prognosis in Relation to Type of Arrhythmia. Many investigators (Chambers, 1946; Billings et al., 1949; Smith et al., 1951; Beard et al., 1960; Imperial et al., 1960; Griffith, Leak, and Hegde, 1962) found atrial fibrillation to be associated with an increased mortality, though others (Mintz and Katz, 1947; Julian et al., 1964) failed to observe this. Askey and Neurath (1945) found that, if atrial fibrillation was transient and lasted less than 24 hours, the mortality was little affected, whereas, if it was more persistent, the mortality increased. In our series the mortality in this group whose dominant arrhythmia was supraventricular tachycardia did not differ significantly from that of the group as a whole. In all our patients the individual episodes of atrial fibrillation lasted less than 24 hours. In the single patient who died, both the large size of the infarct, with aneurysm formation, and chronic heart failure, after re-establishment of sinus rhythm, contributed to the fatal outcome.

Nodal rhythm and atrio-ventricular dissociation carried a good prognosis in three patients: the fourth died, but he had developed a cardiac aneurysm with chronic heart failure. We feel that this transient arrhythmia, which ceased several weeks before death, was merely an incidental factor in a patient 
whose death was due to extensive myocardial damage.

Supraventricular bradycardia with vasovagal attacks has carried a good prognosis in our series. We believe that this in part reflects improved treatment, nursing patients flat prophylactically to maintain blood pressure, and raising the legs and giving atropine immediately vasovagal symptoms occur. Such patients are sometimes described as "shocked" and have in the past presented difficulties in management. Provided the myocardial pump remains sound and simple physical measures are instituted to maintain blood pressures and combat excessive vagal activity, the prognosis appears to be good. The single patient who died in this group had a severe infarct, was in congestive failure, and was suffering from acute anuria, requiring dialysis, and his death was unrelated in time to the vasovagal attack.

Short bursts of ventricular tachycardia in patients whose general condition was good were an infrequent arrhythmia in our series, but in both our patients the outcome was satisfactory. Transitory ventricular tachycardia was met as a terminal rhythm preceding ventricular fibrillation or standstill in severely ill patients (Jouvé et al., 1954).

The prognosis in heart block developing after acute infarction has been found to vary widely in different series, the mortality rate being between 36 per cent (Gilchrist, 1958) and 100 per cent (Mintz and Katz, 1947; Woods and Barnes, 1942). The average mortality in 154 cases collected from 11 series was 48 per cent (Master et al., 1938; Woods and Barnes, 1942; Mintz and Katz, 1947; Smith et al., 1951 ; Penton et al., 1956; Condry and Thompson, 1957; Gilchrist, 1958; Imperial et al., 1960; Beard et al., 1960; Courter et al., 1963). All the patients in our series died. One might have survived, but succumbed to a second fatal arrhythmia, terminally in ventricular fibrillation, after initial successful treatment of heart block by endocardial pacing.

We feel that to consider complete heart block as a single entity from the point of view of prognosis is misleading. Many different degrees of associated myocardial damage and hæmodynamic disability may be met. A fall in blood pressure with the onset of complete heart block is probably a bad prognostic sign, indicating that the heart is unable to increase its stroke output sufficiently to compensate for the bradycardia. Where the blood pressure is well maintained, the chances of recovery are better. Factors such as these, together with other general clinical considerations, including the presence of heart failure and size of the infarct, probably account for the widely varying mortality figures reported for complete heart block.

The prognosis with uninterrupted sinus rhythm, or extrasystoles only, was found to be good, reflecting in general the relatively minor nature of the infarcts in these patients. Only one patient died without some premonitory arrhythmia: in his case, death was sudden and unexpected, in which a short burst of agonal complete heart block followed by asystole was observed. The association of an old posterior with one recent and one very recent anterior infarct in this patient's heart may have been an important factor predisposing to the onset of complete heart block, which in his case proved to be an agonal arrhythmia.

\section{SUMMARY}

The cardiac rhythm in 50 consecutive patients suffering from acute cardiac infarction was studied clinically and with continuous electrocardiographic monitoring. The central venous, or brachial arterial, pressure was recorded in seven patients during an arrhythmia. Necropsies were obtained in nine of the 12 patients who died. Injection of the coronary arterial tree after death was performed in six, and special examination of the sinoatrial node and atrio-ventricular node and bundle was made in seven.

The incidence, natural history, and clinical course of the arrhythmias after acute cardiac infarction are presented, with special emphasis on their hæmodynamic effects. The arrhythmias have been divided into certain broad clinical groups. Their xtiology, in relation to prodromal extrasystoles and to the underlying pathology, is discussed. Finally, their prognosis and management are described.

We should like to thank the nursing staff, and the staffs of the Department of Diagnostic Radiology, and of Biochemistry for help and co-operation in this study. We are also grateful to Mr. Peter Burgess and Miss Jean Powell for technical assistance.

\section{REFERENCES}

Askey, J. M., and Neurath, O. (1945). The prognostic significance of auricular fibrillation in association with myocardial infarction. Amer. Heart $\mathcal{F}$., 29, 575.

Beard, O. W., Hipp, H. R., Robins, M., Taylor, J. S., Ebert, R. V., and Beran, L. G. (1960). Initial myocardial infarction among 503 veterans. Five-year survival. Amer. F. Med., 28, 871.

Billings, F. T., Kalstone, B. M., Spencer, J. L., Ball, C. O. T., and Meneely, G. R. (1949). Prognosis of acute myocardial infarction. Amer. F. Med., 7, 356.

Blondeau, M., Rizzon, P., and Lenègre, J. (1961). Les troubles de la conduction auriculo-ventriculaire dans l'infarctus myocardique récent. II. Étude anatomique. Arch. Mal. Ceur, 54, 1104. 
Braunwald, E., and Frahm, C. J. (1961). Studies on Starling's law of the heart. IV. Observations on the hemodynamic functions of the left atrium in man. Circulation, 24, 633.

Burchell, H. B. (1963). Analogy of electronic pacemaker and ventricular parasystole with observations on refractory period, supernormal phase, and synchronization. Circulation, 27, 878.

Burn, J. H. (1960). The cause of fibrillation. Brit. med. F., 1, 1379.

Chambers, W. N. (1946). Acute myocardial infarction. A study of 100 consecutive cases. New Engl. F. Med., $235,347$.

Condry, R. J., and Thompson, A. C. (1957). Complete heart block in acute myocardial infarction. W. Va med. $\mathcal{F}$., 53, 139.

Courter, S. R., Moffat, J., and Fowler, N. O. (1963). Advanced atrio-ventricular block in acute myocardial infarction. Circulation, 27, 1034.

Gilchrist, A. R. (1958). Clinical aspects of high-grade heart-block. Scot. med. F., 3, 53.

Griffith, G. C., Leak, D., and Hegde, B. (1962). Conservative anticoagulant therapy of acute myocardial infarction. Ann. intern. Med., 57, 254.

Harrison, C. V., and Wood, P. (1949). Hypertensive and ischæmic heart disease: a comparative clinical and pathological study. Brit. Heart f., 11, 205.

Hellerstein, H. K., and Turell, D. J. (1964). The mode of death in coronary artery disease : an electrocardiographic and clinicopathological correlation. In Sudden Cardiac Death, ed. B. Surawicz, and E. D. Pellegrino. Grune and Stratton, New York.

Hudson, R. E. B. (1960). The human pacemaker and its pathology. Brit. Heart f., 22, 153.

Imperial, E. S., Carballo, R., and Zimmerman, H. A. (1960). Disturbances of rate, rhythm and conduction in acute myocardial infarction: a statistical study of 153 cases. Amer. F. Cardiol., 5, 24.

James, T. N. (1961). Myocardial infarction and atrial arrhythmias. Circulation, 24, 761 .

- (1962). Arrhythmias and conduction disturbances in acute myocardial infarction. Amer. Heart f., 64, 416.

Jouvé, A., Senez, J., and Pierron, J. (1954). Diagnostic Électrocardiographique, 2nd ed. Masson, Paris.

Julian, D. G., Valentine, P. A., and Miller, G. G. (1964). Disturbances of rate, rhythm and conduction in acute myocardial infarction. Amer. F. Med., 37, 915.

Kouwenhoven, W. B., Jude, J. R., and Knickerbocker, G. G. (1960). Closed-chest cardiac massage. F. Amer. med. Ass., 173, 1064.

Lev, M., Widran, J., and Erickson, E. E. (1951). A method for histopathologic study of the atrio-ventricular node, bundle and branches. Arch. Path., 52, 73.

Lodge-Patch, I. (1951). Ageing of cardiac infarcts, and its influence on cardiac rupture. Brit. Heart $\mathcal{F} ., 13,37$.

Lown, B., Amarasingham, R., and Neuman, J. (1962). New method for terminating cardiac arrhythmias. Use of synchronized capacitor discharge. f. Amer. med. Ass., $182,548$.

Lumb, G., and Hardy, L. B. (1964). Technique for dissection and perfusion of heart. Arch. Path., 77, 233.

McMichael, J., and Parry, E. H. O. (1960). Prognosis and anticoagulant prophylaxis after coronary occlusion. Lancet, 2, 991.

Master, A. M., Dack, S., and Jaffe, H. L. (1937). Disturbances of rate and rhythm in acute coronary artery thrombosis. Ann. intern. Med., 11, 735.

,-- and - (1938). Partial and complete heart block in acute coronary artery occlusion. Amer. F. med. Sci., 196, 513.

Mintz, S. S., and Katz, L. N. (1947). Recent myocardial infarction; an analysis of 572 cases. Arch. intern. Med., 80, 205.

Peel, A. A. F., Semple, T., Wang, I., Lancaster, W. M., and Dall, J. L. G. (1962). A coronary prognostic index for grading the severity of infarction. Brit. Heart $\mathcal{F}$., 24, 745.

Penton, G. B., Miller, H., and Levine, S. A. (1956). Some clinical features of complete heart block. Circulation, 13,801 .

Pick, A., and Dominguez, P. (1957). Nonparoxysmal A-V nodal tachycardia. Circulation, 16, 1022.

Robinson, J. S., Sloman, G., and McRae, C. (1964). Continuous electrocardiographic monitoring in the early stages after acute myocardial infarction. Med.F. Aust., $1,427$.

Rosenbaum, F. F., and Levine, S. A. (1941). Prognostic value of various clinical and electrocardiographic features of acute myocardial infarction. I. Immediate prognosis. Arch. intern. Med., 68, 913.

Samet, P., Jacobs, W., Bernstein, W. H., and Shane, R. (1963). Hemodynamic sequelæ of idioventricular pacemaking in complete heart block. Amer. F. Cardiol., 11, 594.

Seldinger, S. I. (1953). Catheter replacement of the needle in percutaneous arteriography: a new technique. Acta radiol. (Stockh.), 39, 368.

Smirk, F. H., and Palmer, D. G. (1960). A myocardial syndrome. With particular reference to the occurrence of sudden death and of premature systoles interrupting antecedent T waves. Amer. F. Cardiol., 6, 620.

Smith, F. J., Keyes, J. W., and Denham, R. M. (1951). Myocardial infarction: a study of the acute phase in 920 patients. Amer. F. med. Sci., 221, 508.

Spang, K. (1957). Rhythmusstörungen des Herzens. Georg Thieme, Stuttgart.

Webb, J. L., and Hollander, P. B. (1956). The action of acetylcholine and epinephrine on the cellular membrane potentials and contractility of rat atrium. Circulat Res., 4, 332 .

Woods, R. M., and Barnes, A. R. (1942). Factors influencing immediate mortality and acute coronary occlusion. Amer. Heart F., 24, 4.

\section{APPENDIX}

Although attaching little importance to statistics based on a small series, we none the less append figures for the mortality rate and also for the success rate of resuscitation in patients with cardiac infarction admitted to the acute coronary care unit between November 1963 and March 1966.

Total number of consecutive patients admitted $=94$

Deaths during this hospital admission $\quad=16$

$$
\text { Mortality rate }=17 \text { per cent }
$$

Episodes of ventricular fibrillation occurred in 13 patients, in 10 of whom attempts at resuscitation were made. A total of 18 episodes of ventricular fibrillation were treated, using external cardiac massage and D.C. conversion in 17, and cardiac massage alone (with success) in one. Resuscitation was successful in restoring sinus rhythm in 17 of the 18 episodes, but an effective heart beat was only restored in 15 episodes. The maximum number of episodes successfully treated in one patient was five. 
Four patients left hospital after successful resuscitation from ventricular fibrillation. Nine died, in six of whom resuscitation from one or more attacks of ventricular fibrillation had been carried out.

Episodes of ventricular standstill occurred in six patients; in three patients the episodes terminated spontaneously and in three resuscitation was given. A total of 10 episodes of ventricular standstill were treated by external cardiac massage, with reversion to sinus rhythm in every episode and re-establishment of an effective heart beat in nine. The maximum number of episodes successfully treated in one patient was five. Only one patient left hospital after episodes of ventricular arrest, but these had not required cardiac massage.

Internal cardiac pacing was carried out in five out of six patients who developed complete heart block. Four were having Stokes-Adams attacks, with episodes of ventricular standstill, and the fifth had shorter episodes of standstill, not associated with unconsciousness. Satisfactory pacing was achieved in only two of these five seriously ill patients. One patient left hospital after a period of successful pacing. 